\title{
Grandes projetos de mineração e direitos territoriais das comunidades locais em Moçambique
}

\section{Large mining projects and territorial rights of local communities in Mozambique}

\begin{abstract}
Albino José Eusébio - Doutorando em Sociologia no Programa de Pós-Graduação em Sociologia e Antropologia da Universidade Federal do Pará (PPGSA/UFPA). Mestre em Ciências Sociais pelo PPGSA/UFPA. Bolsista da Capes. E-mail: albinoeusebio@outlook.com
\end{abstract}

Sônia Barbosa Magalhães - Doutora em Antropologia pela Universidade Federal do Pará e em Sociologia pela Université Paris. Professora no Programa de Pós-Graduação em Sociologia e Antropologia da Universidade Federal do Pará (PPGSA/ UFPA).E-mail: smag@ufpa.br

\begin{abstract}
Resumo
No presente ensaio propusemo-nos - face ao avanço dos grandes projetos de mineração - a fazer uma reflexão sobre a questão fundiária e os direitos territoriais das comunidades locais em Moçambique. A nossa reflexão encontra-se dividida em três pontos. No primeiro, buscamos fazer uma análise crítica do discurso de desenvolvimento, que norteia os grandes projetos de mineração em Moçambique, evidenciando com base nos estudos da Amazônia brasileira o lado obscuro do mesmo. No segundo nos ocupamos por uma análise meramente jurídica sobre as formas de apropriação do território em Moçambique. No terceiro discutimos a questão dos direitos territoriais das comunidades locais face aos deslocamentos compulsórios provocados por grandes projetos. Neste advogamos a necessidade de uma discussão "profunda" sobre os direitos territoriais das comunidades locais, face ao avanço dos grandes projetos, tendo em conta que os deslocamentos compulsórios não são, exclusivamente, um deslocamento espacial, mas também, dos vestígios que reforçam a memória coletiva e da história sociocultural dessas comunidades.
\end{abstract}

\section{Palavras-chave}

Moçambique. Grandes Projetos de Mineração. Direitos Territoriais. Comunidades Locais.

\begin{abstract}
In this paper we proposed to analyze the land question and the territorial rights of local communities in Mozambique, before the advancement of large mining projects. Our reflection is divided into three points. In the first one we seek to make a critical analysis of the development discourse which guides the large mining projects in Mozambique showing based on studies of the Brazilian Amazon the dark side of it. In the second we make a juridical analysis of the appropriation forms of land in Mozambique. In the third we discuss the question of land rights of local communities before the forced displacement caused by large projects. In this point we advocate the necessity of a "thorough" discussion about the territorial rights of local communities, before de advancement of large projects in Mozambique, considering that the forced displacement are not simply a spatial displacement but also of the traces that strengthen memory collective and of the socio-cultural history of these communities.
\end{abstract}

\section{Keywords}

Mozambique. Large Mining Projects. Territorial Rights. Local Communities. 


\section{INTRODUÇÃO}

Nos últimos 10 anos vêm-se verificando em Moçambique grandes transformações socioeconômicas provocadas pelo avanço de grandes projetos de mineração, com destaque para o projeto de Moatize e o projeto de Benga na província de Tete, região centro de Moçambique, dois dos grandes projetos de exploração mineral. O projeto de Moatize é operado pela empresa Vale Moçambique $^{1}$, uma multinacional pertencente à empresa brasileira Vale, com uma licença de exploração, assinada com o Governo Moçambicano em 2007, numa área estimada em aproximadamente 23,780 hectares no distrito de Moatize (MOSCA; SELEMANE, 2011). O projeto Benga operado pelo Rio Tinto², uma empresa com capitais anglo-australianos e possui uma licença de concessão mineira para uma área de 4,560 hectares, com duração de 25 anos (SELEMANE, 2010). Ambas incluem áreas que eram historicamente habitadas.

Um dos efeitos sociais diretos dos dois grandes projetos foi a expropriação do território por meio do deslocamento compulsório das comunidades locais. O Projeto de Moatize, por exemplo, afetou e obrigou ao deslocamento compulsório de 1.365 famílias, transferidas involuntariamente na sua maioria em duas áreas determinadas pela empresa em convênio com o governo local (do distrito de Moatize e da província de Tete), nomeadamente Cateme, que se localiza a 40 $\mathrm{km}$ da Vila Sede de Moatize, para as populações que foram classificadas como rurais - foram classificadas como rurais a famílias que viviam da agricultura e outras atividade "informais" como olearia - e bairro 25 de Setembro na Vila de Moatize para as famílias classificadas como semiurbanas - funcionários e, por exemplo, trabalhadores das diversas empresas (SELEMANE, 2010; MOSCA; SELEMANE, 2011; HRW, 2013).

Estima-se que das 1.365 famílias do Projeto de Moatize, 717 famílias foram deslocadas para Cateme, 289 para o bairro 25 de Setembro, o restante foram deslocados compulsoriamente mediante indenização (MOSCA; SELEMANE, 2011; SELEMANE, 2010; HRW, 2013). Por sua vez, o projeto de Benga operacionalizado pela multinacional Rio Tinto obrigou ao deslocamento compulsório, aproximadamente 600 famílias de Benga, em sua maioria reassentadas em Mwaladzi, localidade kambulatsitsi, que se localiza a $4 \mathrm{~km}$ de

\footnotetext{
1 Importa frisar que a Vale constitui a segunda maior empresa mineradora do mundo com operações em quase todos Estados Brasileiros e em seis continentes (MARSHALL, 2012) incluindo a África, com destaque para as suas atividades em Moçambique.

2 A empresa Rio Tinto constitui uma das maiores empresas de mineração do mundo com presença em aproximadamente 40 países em todo o mundo (HRW, 2013, p. 46). Na África se destaca atualmente a sua presença em Moçambique.
} 
Cateme, o maior centro de reassentamento da Vale, e $40 \mathrm{~km}$ da cidade de Tete, a capital da província de mesmo nome (MOSCA; SELEMANE, 2011).

É diante desta realidade dos deslocamentos compulsórios em Moçambique - expropriação das comunidades locais do seu território, - provocados pelo avanço dos grandes projetos de mineração que no presente ensaio nos propusemos a analisar a questão fundiária e os direitos territoriais das comunidades locais em Moçambique.

O trabalho está dividido em três pontos essenciais, no primeiro, buscamos fazer uma análise crítica da ideia de desenvolvimento, enquanto um discurso que norteia os grandes projetos de mineração, evidenciado com base nos estudos da Amazônia brasileira o lado obscuro dos mesmos - degradação ambiental, usurpação e expropriação do território. No segundo nos ocupamos por uma análise meramente jurídica sobre as formas de apropriação do território em Moçambique. No terceiro e último ponto fazemos uma reflexão sobre a questão dos direitos territoriais das comunidades locais face aos deslocamentos compulsórios provocados por grandes projetos.

\section{GRANDES PROJETOS DE MINERAÇÃO: DO DISCURSO DE DESENVOLVIMENTO À USURPAÇÃO E DEGRADAÇÃO DO TERRITÓRIO}

Os Estados são inventados como modernos e Moçambique não foge a essa lógica. Enxerga-se dentro de uma "linha evolucionista" rumo ao desenvolvimento. "Cego seguidor" duma lógica de desenvolvimento, que tem, por exemplo, nos grandes projetos como um dos setores dinamizadores. Lógica de desenvolvimento essa, que, apesar de se apresentar como universal, é local inerente a uma cultura específica ocidental (SOUZA PINTO; MIGNOLO, 2015). Ou seja, é economicista, eurocêntrica e instrumental.

Economicista, pois, na forma em que é abordada pelos grandes projetos, incluindo os setores governamentais e órgãos locais de poder, se trata de uma perspectiva de desenvolvimento reduzida ao crescimento econômico, centrado em variáveis quantificáveis ignorando as questões "não quantificáveis” tais como a diversidade sociocultural e as lógicas específicas de produção, organização e reprodução social das comunidades locais. Eurocêntrica, na medida em que se baseia no parâmetro ocidental de sociedade como parâmetro universal de reprodução social ignorando a variabilidade dos contextos socioculturais. Instrumental, pois são práticas e discursos acoplados aos interesses de grande capital (VIOLA, 2000). 
Estas três características constituem o cerne do que se denomina de paradigma da modernização. Aliás, é neste contexto da redução do desenvolvimento à modernização que se fundamenta, se olharmos o contexto global, a distinção, por um lado, entre o primeiro mundo, segundo e terceiro, acoplado, segundo Lewis (2005), numa cadeia evolutiva, no sentido darwiniano, onde os primeiros seriam mais desenvolvidos e os últimos pobres. Por outro, entre Norte e Sul fundado num discurso que é fruto da distinção entre sociedades modernas e tradicionais, no sentido durkheminiano, onde os primeiros seriam modernos e os últimos periféricos e tradicionais. Estas distinções caracterizam atualmente o sistema global de poder (LEWIS, 2005).

Nesta lógica de pensamento as sociedades tradicionais, por exemplo, como as próprias sociedades africanas e algumas comunidades tradicionais da Amazônia brasileira, foram e continuam sendo percebidas como um obstáculo ao desenvolvimento (VIOLA, 2000). Pois "estas culturas eram identificadas com atitudes de fatalismo, imobilismo e obscurantismo e com estruturas sociais obsoletas" (LEWIS, 2005, p. 16).

Um das críticas ao paradigma da modernização provém do que se denomina da teoria da dependência. Esta rejeita as ideias evolucionistas da teoria da modernização e centram as suas análises na relação desigual entre Norte "dominador" e o Sul "dominado" em termos comerciais. Estas relações comerciais desiguais são vistas como um amplo processo que cria o subdesenvolvimento dos países periféricos, com destaque para os africanos no âmbito da sua integração no sistema capitalista global (LEWIS, 2005).

Contudo é na teoria do post-development (ESCOBAR, 2000, 2005; PIETERSE, 2000) - este último com uma vertente crítica à própria ideia de postdevelopment - que tem como uma das principais referências o antropólogo Arturo Escobar, em que se encontra uma das mais contundentes abordagens críticas ao "desenvolvimento". Este visto como um discurso e, acima de tudo, como um "discurso" ocidental hegemônico e de dominação global. É por essa razão que a teoria do post-development advoga uma necessidade radical de repensar as concepções e os objetivos de desenvolvimento entendidos como reflexo, de uma ideologia cultural ocidental hegemônica que impõe uma homogeneização de valores materiais, imposição de conhecimento, e cria um nível sem precedente de destruição do ambiente (LEWIS, 2005). Para Arturo Escobar, por exemplo, o discurso do desenvolvimento atua como um novo orientalismo permitindo a invenção do terceiro mundo (VIOLA, 2000).

Para os Estados classificados como de terceiro mundo, como é o caso de Moçambique, o desenvolvimento é um "sonho a ser alcançado desesperadamente" 
e os grandes projetos incentivados por uma política de "desenvolvimento" que vem cada vez mais se centrando, tal como acontece na Amazônia brasileira, na exploração e exportação de commodities representam atualmente uma "esperança", uma "falsa esperança", na melhor das hipóteses.

Um dos efeitos sociais diretos do avanço dos grandes projetos em Moçambique e consequentemente dessa lógica de desenvolvimento são, tal como destacamos na introdução, os deslocamentos compulsórios das comunidades locais. Estas são colocadas numa possibilidade de viver, mas na condição de deixarem de ser o que são (BOURDIEU; SAYAD, 2006). Entendemos por deslocamentos compulsórios como uma situação onde "determinados grupos sociais são obrigados a deixar ou a transferir-se de suas casas e/ou de suas terras" (MAGALHÃES, 2007, p. 14). Trata-se, no caso dos grandes projetos, de um processo de usurpação do território "atenuado" por um discurso "triunfalista de desenvolvimento" que é baseado, tal como vemos destacando, num olhar eurocêntrico homogeneizante e que ignora a diversidade sociocultural, esta vista como uma barreira ao próprio desenvolvimento e modernização (CREWE; HARRISON, 2005).

O discurso triunfalista de desenvolvimento que caracteriza os grandes projetos não pode ser visto de forma dissociada do discurso triunfalista da própria ideia de modernidade, - entendemos neste contexto por modernidade no sentido abordado pela perspectiva dos estudos pós-coloniais e da decolonialidade (SOUZA PINTO; MIGNOLO, 2015; MIGLIEVICH-RIBEIRO, 2014; MATA, 2014); como um projeto de dominação epistêmica, econômica e política do mundo - que esconde, segundo Souza Pinto e Mignolo (2015) horrores como a colonialidade, - uma relação já evidenciada por Aníbal Quijano (2005) - o genocídio dos outros povos, a destruição das diversidades socioculturais (MIGLIEVICH-RIBEIRO, 2014), degradação dos solos, bem como a expropriação ou os deslocamentos compulsórios das comunidades locais.

Trata-se de "contradições, desastrosas e camufladas" (MIGLIEVICHRIBEIRO, 2014, p. 68) por uma “cosmovisão moderna hegemônica”, que caracteriza os grandes projetos de desenvolvimento, por exemplo, em Moçambique e que norteia o discurso desenvolvimentista do Estado Moçambicano e das empresas multinacionais que se anunciam como "salvadores da pátria".

Ao reproduzir o discurso de desenvolvimento acoplado à ideia de modernidade, estes não se dão conta que o mesmo, apesar de se apresentar como universal ou uma realidade objetiva ele é local, é eurocêntrico, muito menos conseguem compreender que depois do pretexto salvacionista e civilizacionista, hoje o lógica desenvolvimentista assume-se de acordo com Souza Pinto e Mignolo (2015) como uma nova forma de dominação e de colonização dos povos. 
Primeiro foi, tal como evidenciam os autores, no continente Americano,

os povos originários desse continente foram os primeiros a sentir mais fortemente o impacto do esforço salvacionista, civilizatório e desenvolvimentista dos europeus ocidentais. Ao argumento de que resistiam às tentativas de salvá-los do paganismo e do primitivismo a que supostamente se encontravam aprisionados, os vários povos e etnias que milenarmente habitavam o continente americano, do sul ao norte, foram desapropriadas de suas terras, removidos e circunscritos a áreas "reservadas", pobres de recursos e impróprias a suas formas de organização econômica e política. Submetidos a um esmagador processo de dominação cultural, suas vozes foram silenciadas, suas memórias - inclusive de resistência - foram apagadas, suas crianças lhes foram arrancadas e internadas em escolas-fábricas de ocidentalizados. Sem passado nem futuro, os que não foram confinados, foram submetidos ao trabalho forçado, e os que sobreviveram ao extermínio - e muitos milhões foram exterminados já nos primeiros contatos com os europeus ocidentais - foram reduzidos à condição de "índios" (SOUZA PINTO; MIGNOLO, 2015, p. 389).

A Amazônia brasileira, por exemplo, seguindo essalógica desenvolvimentista dinamizada principalmente a partir da década 1980, transformou-se em uma zona de expansão do capitalismo industrial, que adentrou a floresta tropical úmida por meio, por exemplo, da exploração mineral, - hoje pelo agronegócio "realizada por diversos grupos empresariais, estatais e privados, secundada por um incipiente processo de industrialização que visou a verticalização da produção mineral e sídero-metalúrgica na região" (SILVA NETO, 2012, p. 18).

Esta expansão capitalista para a Região Amazônica foi realizada, segundo o mesmo autor, totalmente à revelia de um imenso número de grupos sociais que tradicionalmente ocupavam as terras que foram convertidas por essa lógica desenvolvimentista, em espaços de negócios; dentre os quais a grande heterogeneidade de povos indígenas, famílias camponesas emigrantes de várias áreas do Brasil, dentre outras populações tradicionais, secularmente "invisibilizadas", segundo Treccani (2014), desde o tempo colonial.

De acordo com Silva Neto (2012), os projetos de desenvolvimento pensados pelos órgãos de planejamento governamentais para esta região partiram, tal como acontece atualmente em Moçambique, sempre de uma perspectiva produtivista que tomou como forma ideal de organização social da produção a empresa capitalista, cuja instalação requereu naturalmente a apropriação privada de vastas extensões de terras outrora públicas, assim como de florestas primárias e secundárias, tradicionalmente usadas de modo livre ou comunal pelas populações locais, trazendo, junto com algum progresso econômico, inúmeros conflitos e 
tensões sociais (SILVA NETO, 2012). Ou seja, a Amazônia se transformou num território de capital contra o território dos povos (LEROY, 2010) e consequentemente num território de resistência e conflitos entre lógicas distintas de apropriação do território (MESQUITA, 2011; SANT’ANA JÚNIOR, 2014).

Em segundo plano o pretexto salvacionista, civilizacionista e hoje desenvolvimentista atingiu o continente Africano, onde,

à semelhança dos povos originários da América, os diferentes povos e etnias africanas, especialmente as subsaarianas, foram submetidas a um brutal controle e gerenciamento subjetivo e epistêmico, além de econômico e político. Diferentemente de seus consortes americanos, no entanto, por terem sido posicionados, por força de argumentos inicialmente cristãoteológicos e posteriormente científico-biológicos, no mais primitivo estágio da linha de evolução humana articulada no discurso eurocêntrico de modernidade, os subsaarianos, em sua grande parte, foram reduzidos a mera mercadoria, tendo sido comercializados, sobretudo na América, para onde foram massiva- mente exportados e utilizados como mão de obra escrava, até quando, por razões mais econômicas do que éticas, ou melhor, por força de uma ética econômica, foram trocados por trabalhadores assalariados, muitos dos quais imigrados de regiões periféricas da Europa (SOUZA PINTO; MIGNOLO, 2015, p. 390).

Portanto, longe da lógica civilizacionista e da colonização política, hoje o discurso "desenvolvimentista" caracteriza a nova forma de dominação e exploração dos povos, que tem nas empresas capitalistas e os grandes projetos como uns dos atores dinamizadores. É na América e concretamente na Amazônia brasileira que encontramos evidências claras do lado obscuro do projeto desenvolvimentista (COSTA, 2011; SILVA NETO, 2012, ALMEIDA, 2011; LEROY, 2010; FARIAS JÚNIOR, 2010; GAVIRIA, 2013; TRECCANI, 2014), hoje reproduzido no contexto moçambicano, diante da ingenuidade consciente dos setores governamentais, por meio de grandes projetos de desenvolvimento ligados à atividade de exploração mineral.

Farias Júnior (2010) evidencia, por exemplo, que o avanço das atividades de mineração no Município de Oriximiná com o apoio do Estado, por meio da criação de Unidades de Conservação Ambiental, - estes que segundo a realidade evidenciada pelo autor naquela realidade sociocultural, inviabilizam os direitos das comunidades tradicionais quilombolas de demarcação e titulação das suas terras tradicionalmente ocupadas, em detrimento dos interesses empresariais de mineração - põem em causa os próprios interesses ambientais das Unidades de Conservação devido às práticas devastadoras e altamente perigosas ao ambiente naquela região do estado do Pará (FARIAS JÚNIOR, 2010). 
O autor cita, por exemplo, o desastre ambiental ocorrido no Lago Batata, na Bacia do Rio Trombetas, "que entre as décadas de 79 e 89, era utilizado pela empresa MRN como bacia de rejeitos, despejando, aproximadamente 24 milhões de toneladas de rejeitos de lavagem de bauxita que causou danos ambientais incalculáveis e irreversíveis" (FARIAS JÚNIOR, 2010, p. 122), como um dos exemplos de desastre ambiental provocado pelas atividades de exploração mineral naquela região da Amazônia brasileira.

Este fato torna de certa forma, os conflitos entre as comunidades tradicionais e as empresas mineradoras inevitáveis. Aliás, é importante frisar que conflitos envolvendo as comunidades tradicionais e as empresas mineradoras constituem um fenômeno constante na Amazônia brasileira, devido à capacidade de resistências dos primeiros, denunciando, por exemplo, a incompatibilidade das atividades de mineração com as suas práticas históricas de ocupação e uso de território, que afetam as suas condições específicas de produção, organização e reprodução material, cultural e social, conforme constatado por Gaviria (2013), no município de Juriti Velho, no estado do Pará.

$\mathrm{O}$ privilégio dado pelo poder político às atividades mineradoras, e de um modo geral, aos interesses de exploração capitalista, como é o caso das empresas agropecuárias, madeireiras e os grandes projetos industriais e de infraestruturas, nas terras da Amazônia brasileira, é denunciada também por Treccani (2014). Tal como afirma o autor,

nas últimas cinco décadas, com apoio do Estado brasileiro, o capital avançou sempre mais sobre as últimas fronteiras naturais amazônicas disputando territórios com populações indígenas, quilombolas e demais populações tradicionais e locais, transformando as terras e floresta, água, solo e subsolo em 'mercadoria', a ser leiloada na perversa dinâmica das 'leis do mercado’ em que a exploração indiscriminada da natureza e da própria vida humana viraram 'oportunidade de negócio' destruição e conservação, que passam a ter preço (TRECCANI, 2014, p. 162).

A expansão das atividades de mineração está, ainda segundo o autor, entre os responsáveis pela ampliação dos conflitos socioambientais nessa região, sendo a usurpação e a expropriação do território das populações e outras comunidades locais elementos de grande destaque.

A relevância dessas abordagens, que podem parecer desconexas ao nosso horizonte espacial reflexivo, tendo em conta que são inerentes ao contexto da Amazônia brasileira e não moçambicano, reside no fato de evidenciarem que longe do "propagado" desenvolvimento, que norteia os discursos dos atores das empresas nacionais ou multinacionais, bem como dos órgãos governamentais, 
os grandes projetos de mineração apresentam efeitos "catastróficos" como a degradação ambiental, a ampliação de conflitos sociais e acima de tudo, a usurpação e expropriação do território, com efeitos sociais diretos nas comunidades locais.

Se por um lado essas discussões são um "alerta" para uma reflexão profunda sobre a lógica desenvolvimentista que vem sendo adotada em Moçambique, nos últimos anos, que tem nos grandes projetos ligados não só, à mineração, como também, à indústria energética e ao agronegócio, como uns dos setores dinamizadores. Por outro, tornam oportuno um profundo debate sobre os direitos territoriais das comunidades locais naquela realidade sociocultural.

\section{A QUESTÃO FUNDIÁRIA EM MOÇAMBIQUE: É POSSÍVEL FALAR DOS DIREITOS TERRITORIAIS DAS COMUNIDADES LOCAIS?}

O objetivo central nesse tópico é abordar as formas de apropriação do território em Moçambique, problematizando a questão da diversidade sociocultural e buscando refletir como ela se efetiva nos direitos territoriais. Discutir essa questão nos obriga a abordar em primeiro lugar a dicotomia entre a uniformidade ou a visão monista do direito e pluralismo jurídico, - os juristas Jose Heder Benatti (2011) e Deborah Duprat (2007) nos introduzem melhor nessas questões - tendo em conta que é neste último que se amparam, no caso brasileiro, as formas de apropriação coletiva do território.

\subsection{O DIREITO MOÇAMBICANO: VISÃO MONISTA OU PLURALISMO JURÍDICO?}

A visão monista do direito pressupõe a homogeneização do direito por meio de uma visão jurídica oficial, unitária e totalizante (BENAT'TI, 2011). Tratase de uma visão que se fundamenta na lógica imposta pelo direito oficial baseado na compreensão predominante de que só é "considerado jurídico o que o Estado elabora e o restante é pseudo direito ou um direito inferior" (BENATTI, 2011, p. 95). Esta perspectiva jurídica não pode ser vista de forma dissociada da lógica integradora de direito baseada, tal como evidencia Duprat (2007), na colonização da diferença.

No caso específico dos direitos territoriais, importa frisar que é nessa lógica monista e positiva de direito - que para Benatti (2011) reduz a dimensão ampla e complexa do jurídico, - que se ampara a configuração do regime jurídico de propriedade acoplado, exclusivamente, na propriedade individual como único modelo de apropriação do território, ignorando desse modo o direito a 
apropriação comunitária dos recursos, a propriedade comum ou apropriação coletiva do território (BENAT'TI, 2011).

O pluralismo jurídico pressupõe a descolonização da diferença pelo direito homogeneizante (DUPRAT, 2007) e, no que concerne aos direitos territoriais, representa uma nova configuração do regime jurídico de propriedade, alternativo à propriedade individual, como é o caso da propriedade comum (BENATTI, 2011).

O reconhecimento do pluralismo jurídico é o reconhecimento da diversidade sociocultural do Estado nacional e a superação da falsa homogeneidade nacional propagada pela ideia do Estado-Nação, baseado numa lógica da unidade como sinônimo da uniformidade e integração e não do reconhecimento da diferença (CASTELLS, 1999). No caso do Brasil, por exemplo, a promulgação da Constituição Federal de 1988 reafirma o caráter pluriétnico e multicultural do país, que o direito deve ter, segundo Duprat (2007), como marco referencial.

De acordo com a autora, com a Constituição de 1988 passa a se falar no Brasil, não só, dos direitos coletivos inerentes ao lócus étnico e cultural e a lógica específica de produção, organização e reprodução social, como também de espaços de pertencimento e de territórios, com uma configuração distinta da propriedade privava que é de natureza individual com viés da apropriação econômica (DUPRAT, 2007 p. 4). Ou seja, "a Constituição reconhece expressamente direitos específicos a índios e quilombolas, em especial seus territórios. Mas não só a eles. Também são destinatários de direitos específicos os demais grupos que tenham formas próprias de expressão e de viver, criar e fazer" (DUPRAT, 2007, p. 5).

Este fato representa, por um lado, uma vitória dos movimentos de reivindicação e de luta contra a invisibilização social ou cultural, por exemplo, das populações tradicionais com destaque para as comunidades quilombolas e dos povos indígenas, secularmente invisibilizadas e suprimidas pelo Estado Brasileiro, por outro, de todo o processo em que o Direito abandona, de um lado, "a visão atomista do indivíduo e o reconhece como portador de identidades complexas e multifacetadas. De outro, recupera o espaço comum onde são vividas as suas relações definitórias mais importantes" (DUPRAT, 2007, p. 4).

No caso de Moçambique, - um país caraterizado por uma diversidade sociocultural inerente a sua diversidade étnica, ou seja, Moçambique é tal como vários países africanos, pela sua formação violenta inerente aos interesses coloniais, um país multiétnico, multicultural e multilinguístico - a Constituição da República de Moçambique (CRM), se por um lado, reafirma o Estado de direito democrático baseado no pluralismo de expressão, na organização política 
democrática e acima de tudo no respeito e garantia dos direitos e liberdades fundamentais do homem (Art. 3 CRM). Por outro, destaca dentre outros aspectos, o caráter plural do ordenamento jurídico moçambicano, fundado nesse contexto no reconhecimento dos "vários sistemas normativos e de resolução de conflitos que coexistem na sociedade moçambicana" (Art. 4 da CRM).

A questão que permanece, - tendo como inspiração as discussões do contexto brasileiro onde o pluralismo jurídico garante o reconhecimento da diversidade sociocultural do Estado nacional, do caráter pluriétnico e multicultural, e dá amparo legal para a apropriação coletiva do território por parte dos povos indígenas, das comunidades tradicionais, - é relativa à relação que o pluralismo jurídico em Moçambique tem com os direitos do território. Abordar essa questão passa por analisar as formas de apropriação de território em Moçambique.

\subsection{FORMAS DE APROPRIAÇÃO DO TERRITÓRIO EM MOÇAMBIQUE}

A terra é segundo alínea 01 do Art. 109 (CRM), propriedade do Estado, isso significa que ela não pode ser vendida ou alienada, hipotecada ou mesmo penhorada, isso de acordo com o número 2 do mesmo artigo da CRM, conjugado com o Art. 03 da Lei n. 19/97 de 01 de Outubro, que estabelece os "os termos em que se opera a constituição, exercício, modificação, transmissão e extinção de direito de uso e aproveitamento da terra" (Art. 02); Lei de Terras de Moçambique. Ou seja, o direito exclusivo de propriedade que o Estado tem integra não só todos os direitos de propriedade, mas também, a faculdade de determinar, segundo o $\mathrm{n}^{\circ} 15$ do Art. 01 da Lei de Terras, as condições de uso e de aproveitamento da terra, por parte das pessoas singulares ou coletivas.

Neste contexto, a única forma de apropriação é a obtenção do Direito de Uso e Aproveitamento da Terra (DUAT), que pode ser conferido de acordo com a Constituição da República de Moçambique, a título singular conferido pelo Estado a pessoas singulares e a título coletivo, atribuído as pessoas coletivas (n. 02, Art. 110 CRM). Incluindo a apropriação coletiva da terra pelas comunidades locais, tal como evidencia a Lei de Terras nos seus artigos 10, 12, 13, 15, 24, respectivamente.

A Lei de Terras estabelece três formas de ocupação da terra: primeiro a ocupação por pessoas singulares e pelas "comunidades locais", segundo as normas e práticas costumeiras; segundo, a ocupação por pessoas singulares nacionais - quaisquer cidadãos de nacionalidade moçambicana - que, de boa fé, estejam a utilizar a terra há pelo menos dez anos; e terceiro mediante autorização pelo Estado, respectivo do pedido de uso e aproveitamento da terra apresentado por pessoas singulares ou coletivas. E nesta terceira forma, que se encontra 
segundo ACIS (2012) a única possibilidade de obtenção de DUAT por parte das pessoas singulares e coletivas estrangeiras. Incluindo as empresas multinacionais e em consonância com as normas específicas de cada atividade de exploração.

Definem-se no âmbito da Lei de Terras como "comunidades locais" o "agrupamento de famílias e indivíduos, vivendo numa circunscrição territorial de nível de localidade ou inferior, que visa à salvaguarda de interesses comuns através da proteção de áreas habitacionais, áreas agrícolas, sejam cultivadas ou em pousio, florestas, sítios de importância cultural, pastagens, fontes de água e áreas de expansão" (n. 01 do Art. 01).

O título de ocupação coletiva por parte das comunidades locais é emitido, tal como nas restantes possibilidades de obtenção de DUAT, pelos Serviços Públicos de Cadastro (n. 01 Art. 13), e é nominativo de acordo com a denominação adoptada pelas próprias comunidades (n. 04 Art. 13). Um fato que importa destacar é que a falta de titulação - documento emitido pelos serviços públicos de cadastro, gerais ou urbanos, que serve de comprovativo do direito de uso e aproveitamento da terra - ou de registro, não prejudica o direito de uso e aproveitamento da terra adquirido pelas comunidades locais por ocupação, desde que essa ocupação possa ser comprovada (n. 02 do Art. 13 e art. 14 da Lei de Terras). E essa comprovação pode ser feita, por exemplo, pela prova testemunhal dos membros, homens e mulheres, das comunidades locais, conforme alínea b do art. 15 da Lei Terras.

O reconhecimento dado às comunidades locais ao uso e aproveitamento coletivo da terra implica, por um lado, a consagração pela Lei de Terras dos direitos costumeiros (CAMBAZA, 2009) e consequentemente do pluralismo jurídico previsto no artigo 04 da CRM. E, por outro, o reconhecimento dos diretos territoriais inerentes à ocupação tradicional e histórica.

Torna-se imprescindível clarificar do que estamos falando quando nos referimos ao território e aos direitos territoriais. Esse é um dos aspetos que nos ocuparemos a seguir, ao mesmo tempo em que faremos uma reflexão crítica sobre os deslocamentos compulsórios das comunidades locais, apresentando desse modo as notas conclusivas.

\section{A QUESTÃO DOS DIREITOS DO TERRITÓRIO E OS DESLOCAMENTOS COMPULSÓRIOS POR GRANDES PROJETOS: NOTAS CONCLUSIVAS}

O conceito de território das comunidades locais abrange, - tal como podemos constatar na vasta literatura, seja ela jurídica ou socioantropológica, 
sobre as comunidades tradicionais e povos indígenas na Amazônia, (BRINGAS, 2006; VERDUM, 2011; MESQUITA, 2011; PRIOSTE; ALVES; CAMERINI, 2011; INGLEZ DE SOUSA, 2012; CRUZ, 2013; BECKER, 2014; ALMEIDA, 2011; 2014; TRECCANI, 2014, só para citar alguns.) - categorias como pertencimento, simbolismo, significado, história do grupo e acima de tudo identidade e autorreconhecimento. O reconhecimento de direitos territoriais das comunidades locais implica o reconhecimento dessa pluralidade de categorias.

Portanto falar do território das comunidades locais é falar de um espaço significado e transformado por meio das formas específicas de apropriação, uso, controle e atribuição de significados via formas de vivência e de identificação com o meio ambiente, por parte de um determinado grupo coletivo (BAINES, 2014; GODOI, 2014). O território é resultado de um investimento material e simbólico e se exprime por um sistema de representações e princípios de organização social, econômica, política e cultural, específicos de cada grupo social e geridos, por exemplo, por uma lógica de "pertencimento e de parentesco". Ou seja, "o território antes de se exprimir por uma ligação ao espaço é uma relação entre as pessoas e se refere a uma organização do espaço carregada de história" (GODOI, 2014, p. 13) e não pode ser entendido fora desse contexto. O território das comunidades locais é um produto histórico.

Isso implica que a nossa percepção de território se encontra longe das concepções que o compreendem, exclusivamente, como sinônimo de espaço, ou simplesmente como “fonte de recursos' disputados ou, ainda, de elementar 'apropriação da natureza” (GODOI, 2014, p. 10). Talvez o nosso entendimento se aproxime mais para o que a antropóloga Edna Alencar (2002; 2007; 2013) denomina de "lugar", visto por ela, como um espaço socialmente significativo, construído e transformado pelo trabalho das gerações passadas e é nele onde se inscreve a história do grupo.

Não existe, segundo a autora, um grupo social que não tenha alguma relação com o lugar. A relação que o lugar tem com a memória social, a história das gerações passadas garante o vínculo de pertencimento e serve de fator dissuasor - para alguns grupos sociais - à mobilidade para outros locais, tal como foi constatado pela autora na sua pesquisa onde buscou compreender o processo de afirmação da identidade dos moradores de São João, um povoado situado na área Reserva de Desenvolvimento Sustentável Mamirauá, região de várzea do médio Solimões, estado do Amazonas, que convive permanentemente com o fenômeno de "terra caída" (ALENCAR, 2002; 2007; 2013).

De acordo com Alencar (2007, p. 98), 
quando o grupo social abandona um lugar, o lugar deixa de existir e se perdem os fios da história do grupo que lhe deu origem. Portanto é o grupo social que constrói e dá significado ao lugar, e cada grupo constrói sua identidade a partir dos vínculos de parentesco que unem as famílias entre si e estas com o lugar aberto pelos ancestrais. O pertencimento ao lugar, e a um grupo de parentesco garante o acesso ao território e aos recursos naturais, e funciona como um mapa cognitivo que orienta as relações entre as pessoas e entre essas e o ambiente.

Neste contexto, podemos afirmar que os deslocamentos compulsórios das populações por grandes projetos ligados, principalmente as atividades extração mineral não são, simplesmente, um deslocamento espacial, mas sim um deslocamento dos vestígios que reforçam a memória coletiva e de toda uma história social de um grupo, em todos os seus aspetos culturais, sociais, simbólicos, econômicos, bem como dos aspetos ligados à lógica própria de produção, organização e reprodução social.

Isso introduz no debate sobre os direitos de território em Moçambique, principalmente, numa altura em que se vem verificando o avanço dos grandes projetos ditos de desenvolvimento ligados à mineração, à indústria energética e ao agronegócio. A reflexão na arena pública dessa pluralidade de categorias como pertencimento, memória coletiva, história do grupo, identidade, entre outros aspetos culturais e simbólicos, invisíveis para grandes empresas multinacionais e para o Estado, cego por uma falsa esperança de desenvolvimento que traduz o discurso dos grandes projetos.

No discurso de desenvolvimento dos grandes projetos está patente o privilégio do domínio econômico e ignorância "propositada" da diversidade sociocultural, e das lógicas específicas de organização, produção e reprodução social das comunidades locais afetadas. O desrespeito pela diversidade sociocultural conduz à reestruturação das formas de organização social das comunidades. Este fato que se verifica primeiro, pela disciplina do espaço como critério para disciplinar as lógicas de vida das pessoas, pondo em causa as estruturas originais das comunidades, como o caso das redes de parentesco e reciprocidade (COLSON, 1971). A disciplina de espaço é impositiva e evidencia o caráter autoritário dos deslocamentos compulsórios. Os constantes abandonos dos locais de reassentamento, tal como foi constatado nas pesquisas etnográficas de Colson (1971) entre os Gwembe Tongas, na Zâmbia, e de Magalhães (2007), em 'Tucuruí, são de certo modo uma forma de resistência a essa imposição.

Em segundo lugar o desrespeito pela diversidade sociocultural se evidencia pelo discurso de melhoria de vida, fundado somente na ideia de modernização. Neste contexto, as empresas e os governos locais se veem, usando as palavras 
de Bourdieu e Sayad (2006) como "atores emancipatórios" que buscam dar o privilégio das comunidades viverem, na condição, não só, de deixarem os seus territórios, mas também de deixarem de ser o que são; deixarem a sua “identidade", o que evidencia, mais uma vez, a lógica homogeneizadora e autoritária que caracteriza a expropriação do território das comunidades locais por parte dos grandes projetos.

Embora a Constituição da República de Moçambique destaque o pluralismo jurídico e a Lei de Terras reafirme o direito de uso e aproveitamento da terra para as comunidades locais por ocupação, a realidade evidencia que pouco se tem feito por parte do Estado para o incentivo a essa lógica de apropriação do território; o que contribui para a prevalência da apropriação singular ou da propriedade individual. Cria-se desse modo, usando as palavras de Costa (2011, p. 79), espaço para a configuração de uma teia de mecanismo para a transferência para o domínio privado de extensões de terras ocupadas pelas comunidades locais.

Isso pode transformar Moçambique num território de capital contra o território dos povos (LEROY, 2010) e consequentemente, tal como vem se verificando, num território de conflitos entre as comunidades locais e as empresas de exploração capitalista e alguns setores do governo que insistem em transformar o espaço e seus recursos em plena mercadoria, passível, usando as palavras de Zhouri e Oliveira (2007), de apropriação privada para geração de riqueza destinada à exportação.

Embora a falta de título ou registro não prejudique o direito de uso e aproveitamento da terra das comunidades locais inerentes à ocupação, a titulação do direito coletivo de uso e aproveitamento da terra pode reforçar o sentimento de pertencimento e de identidade das comunidades locais moçambicanas aos respectivos territórios historicamente ocupados, o que pode permitir uma melhor participação dessas comunidades na gestão dos recursos naturais, como também, no processo de negociação com as empresas multinacionais no âmbito do avanço dos grandes projetos em Moçambique.

Gostaríamos de terminar com um parágrafo que reflete o nosso apelo:

Em universo social marcado pelo dificilmente contestável poder dos fazendeiros, dos empresários do agronegócio, o direito dos "pequenos" [...], na maioria das vezes, não é reconhecido como um direito, nem mesmo como sujeitos com capacidade de tornar a terra produtiva. Mais grave ainda são vistos como "sujeitos biologizados", uma mera extensão dos recursos naturais (COSTA, 2011, p. 82).

Moçambique está a caminhar a passos largos para essa triste realidade. 


\section{REFERÊNCIAS}

ALENCAR, E. F. Nesse tempo não existia essas ilhas por ali: sobre modos de perceber o ambiente e narrar o passado. Iluminuras, Porto Alegre, v. 14, n. 34, p. 11-32, 2013.

Paisagens da memória: narrativa oral, paisagem e memória social no processo de construção da identidade. Teoria \& Pesquisa, São Carlos-SP, v. XVI, p. 43-56. 2007.

Terra caída: encante, lugares e identidades. 2002. 245f. Tese (Doutorado em Antropologia) - Departamento de Antropologia, Universidade de Brasília, Brasília, 2002.

ALMEIDA, A. W. B. Cartografia Social na Amazônia: os significados de território e o rito de passagem da "proteção" ao "protecionismo". In: SIFFERT, N.; CARDOSO, M.; MAGALHÃES, W. A.; LASTRES, H. M. M. (Org.). Um olhar territorial para o desenvolvimento: Amazônia. Rio de Janeiro: BNDES, 2014. p. 350-369.

Territórios Quilombolas e Conflitos: comentários sobre povos e comunidades tradicionais atingidos por conflitos de terra e atos de violência no decorrer de 2009. In:_ (Org.). Os Quilombos e as Novas Etnias. Manaus: UEA Edições, 2011. p. 170-187.

A reconfiguração das agroestratégias: novo capítulo da guerra ecológica. In: SAUER, S.; ALMEIDA, W. (Org.). Terras e territórios na Amazônia. Brasília: Editora Universidade de Brasília, 2011. p. 27-44.

ACIS - Associação de Comércio e Indústria. O quadro legal para o reconhecimento e obtenção de Direitos de Terras em áreas rurais em Moçambique. Um guia para a legalização da ocupação. Edição III, 2012. Disponível em: <http://www.acismoz.com/lib/services/publications/docs/ Acesso $\% 20$ Terra $\% 20$ Rural $\% 20$ Edicao $\% 20 I I I \% 20$ Portugues.pdf $>$. Acesso em: 27 jan. 2016.

BAINES, S. G. Territórios, territorialização, territorialidades indígenas e os direitos à terra. Raízes, Porto Alegre, v. 34, n. 02, p. 17-25, 2014.

BECKER, B. K. A Amazônia como um território estratégico e os desafios das políticas públicas. In: SIFFERT, N.; CARDOSO, M.; MAGALHÃES, W. A.; LASTRES, H. M. M. (Org.). Um olhar territorial para o desenvolvimento: Amazônia. Rio de Janeiro: BNDES, 2014. p. 396-401. 
BENATTI, J. H. Propriedade comum na Amazônia: acesso e uso dos recursos naturais pelas populações tradicionais". In: SAUER, S.; ALMEIDA, W. (Org.). Terras e territórios na Amazônia. Brasília: Editora Universidade de Brasília, 2011. p. 93-113.

BOURDIEU, P.; SAYAD, A. A dominação colonial e o sabir cultural. Rev. Sociol. Polít, Curitiba, n. 26, p. 41-60, 2006.

BRINGAS, A. M. Territorialidades indígenas. Hiléia: Revista de Direito Ambiental da Amazônia, Manaus, v. 4, n. 7, p. 123-148, 2006.

CAMBAZA, V. A Lei de Terras, de Minas e os Direitos Consuetudinários. Conference Paper $\mathrm{N}^{\circ}$ 12. In: CONFERENCIA DO IESE, 2. Dinâmicas da Pobreza e Padrões de Acumulação Económica em Moçambique. Maputo: IESE, 2009. Disponível em: < http://www.iese.ac.mz/lib/publication/II_conf/ CP12_2009_Cambaza.pdf>. Acesso em: jan. 2016.

CASTELLS, M. O poder da identidade. In: . (Org.) A era da informação economia sociedade e cultura. São Paulo: Paz e Terra, 1999. v. 2.

COLSON, E. The social consequences of resettlement. The impact of the Kariba resettlement upon the Gwembe Tonga. Manchester: Manchester University Press, 1971.

COSTA, S. M. G. Agronegócio e Terras na Amazônia: conflitos sociais e desterritorialização após a chegada da soja na região do Baixo Amazonas no Pará. In: SAUER, S.; ALMEIDA, W (Org.). Terras e Territórios na Amazônia. Brasília: Editora Universidade de Brasília, 2011. p. 69-89.

CREWE, E.; HARRISON, E. Seeing culture as a barrier. In: EDELMAN, M.; HAUGERUD, A. (Ed.). The anthropology of development and globalization: from classical political economy to contemporary neoliberalism. Malden: Blackwell Publishing, 2005. p. 232-234.

CRUZ, V. C. Das lutas por redistribuição de terra às lutas pelo reconhecimento de territórios: uma nova gramática das lutas sociais? In: ACSELRAD, H. (Org.). Cartografia social, terra e território. Rio de Janeiro: IPPUR/UFRJ, 2013. p. 119-176.

DUPRAT, D. O Direito sobre o marco da plurietnicidade/multiculturalidade. In: _- (Org.). Pareceres jurídicos: direito dos povos e comunidades tradicionais. Manaus: UEA, 2007. p. 9-19. 
ESCOBAR, A. Imagining a post-development era? In: EDELMAN, M.; HAUGERUD, A. (Ed.). The anthropology of development and globalization: from classical political economy to contemporary neoliberalism. Malden: Blackwell Publishing, 2005. p. 341-351.

El lugar de la naturaleza y la naturaleza del lugar: globalization o posdesarrollo. In: VIOLA, A. (Ed.). Antropología del desarrollo. Barcelona: Paidós, 2000. p. 169-216.

FARIAS JÚNIOR, E. A. Unidades de Conservação, mineração e concessão florestal: os interesses empresariais e a intrusão de territórios quilombolas no Rio Trombetas. In: ALMEIDA, A. W. B. (Org.). Cadernos de Debates Nova Cartografia Social. Territórios Quilombolas e Conflitos. Manaus: UEA Edições, 2010. p. 116-127.

GAVIRIA. E. M. Mineração e regulação social na Amazônia: o caso da mineradora Alcoa e as comunidades de Juruti Velho, Pará. In: ACSELRAD, H. (Org.). Cartografia social, terra e território. Rio de Janeiro: IPPUR/UFRJ, 2013. p. 201-273.

GODOI, E. P. Territorialidade: trajetória e usos do conceito. Raízes, Porto Alegre, v. 34, n. 02, p. 8-16, 2014.

HRW - Human Rights Watch. O que é uma casa sem comida: o boom da mineração em Moçambique e o reassentamento. EUA, 2013. Disponível em: <https://www.hrw.org/sites/default/files/reports/mozambique0513port_ ForUpload_0.pdf.> Acesso em: 04 jul. 2014.

INGLEZ DE SOUSA, C. N. Dimensão fundiária da gestão territorial de Terras Indígenas no Brasil. In: INGLEZ DE SOUSA, C. N. ALMEIDA, F. V. R. (Org.). Gestão territorial em terras indígenas no Brasil. Brasília: Ministério da Educação, Secretaria de Educação Continuada, Alfabetização, Diversidade e Inclusão; Unesco, 2012. p. 76-124.

LEROY, J. P. Amazônia: território de capital e território de povos. In: ZHOURI, A.; LASCHEFSKI. K. (Org.). Desenvolvimento e conflitos ambientais. Belo Horizonte: UFMG, 2010. p. 92-113.

LEWIS, D. Anthropology and development: an uneasy relationship. In: LSE research online. London: 2005. 15 p. Disponível em: <https://core.ac.uk/ download/files/67/92474.pdf>. Acesso em: 20 set. 2015. 
MARSHALL, J. Megaprojetos de mineração e trabalho: trabalhar para Vale a pior empresa do mundo: casos do Canadá, Brasil e Moçambique. In: CONFERÊNCIA DO INSTITUTO DE ESTUDOS SOCIAIS ECONÔMICOS-IESE, 3. Maputo: IESE, 2012. Disponível em <http:/ /www.iese.ac.mz/lib/publication/ III_Conf2012/IESE_IIIConf_Paper21.pdf>. Acesso em: 04 jul. 2014.

MATA, I. Estudos pós-coloniais: desconstruindo genealogias eurocêntricas. Civitas, Porto Alegre, v. 14, n. 01, p. 27-42, 2014.

MESQUITA B. A. Conflitos Territoriais na Amazônia na era do capital. In: SHIRAISHI NETO, Joaquim. (Org.). Meio ambiente, território \& práticas jurídicas: enredos em conflito. São Luís: EDUFMA, 2011. p. 53-84.

MIGLIEVICH-RIBEIRO, A. Por uma razão decolonial: desafios ético-políticoepistemológicos à cosmovisão moderna. Civitas, Porto Alegre, v. 14, n. 01, p. 66-80, 2014.

MOSCA, J.; SELEMANE, T. EL Dorado Tete: Os megaprojetos de mineração. Maputo: Centro de Integridade Pública-CIP, 2011.

PIETERSE, J. N. “After post-development”. Third World Quarterly, v. 21, n. 2, p. 175-191, 2000. Disponível em: <http://www.uvm.edu/ bgreene1/ Bibliography2014/Topic04/PieterseAfterPostDevl.pdf $>$. Acesso em: 20 set. 2015.

PRIOSTE, F. G. V., ALVES, C. C. N., CAMERINI, J. C. B. Quem tem medo da Constituição Federal? Quilombos e o direito ao território. In: SAUER, S.; ALMEIDA, W. (Org.) Terras e Territórios na Amazônia. Brasília: Editora Universidade de Brasília, 2011. p. 297-316.

QUIJANO, Aníbal. Colonialidade do poder, eurocentrismo e América Latina. In: LANDER, E. (Org.). A colonialidade do saber: eurocentrismo e ciências sociais. Perspectivas latino-americanas. Buenos Aires: CLACSO, 2005. p. $107-130$.

SANT'ANA JÚNIOR, H. Projetos de desenvolvimento e a criação de reservas extrativistas: estratégias de luta de grupos sociais locais no Acre e no Maranhão. In: ESTERCI, N; SANT'ANA JÚNIOR. H; TEISSERENC, M. (Org.) Territórios socioambientais na Amazônia Brasileira. Rio de Janeiro: 7 Letras, 2014. p. 105-136.

SELEMANE, T. Questões a volta da mineração em Moçambique: Relatório de monitoria das atividades mineiras em Moma, Moatize, Manica e Sussundenga. Maputo: Centro de Integridade Pública-CIP, 2010. 
SILVA NETO, N. M. Quebradeiras e carvoeiros: a transformação do extrativismo de coco babaçu nas terras do Araguaia-Tocantins. 2012. 271f. Tese (Doutorado em Antropologia) - Instituto de Filosofia e Ciências Humanas, Universidade Federal do Pará, Belém, 2012.

SOUZA PINTO, J. R.; MIGNOLO, W. D. A modernidade é um fato universal? Reemergência, desocidentalização e opção decolonial. Civitas, Porto Alegre, v. 15, n. 3, p. 381-402, 2015. DOI: http://dx.doi.org/10.15448/19847289.2015.3.20580.

TRECCANI, G. D. Populações tradicionais e mineração. In: DIAS, J. C.; GOMES, M. A. M. (Org.). Direito e desenvolvimento. Rio de Janeiro; Belém; São Paulo: Forense, CESUPA e Método, 2014. p. 161-190.

VERDUM, R. Terras, territórios e a livre determinação territorial indígena. In: SAUER, S.; ALMEIDA, W. (Org.) Terras e territórios na Amazônia. Brasília: Editora Universidade de Brasília. 2011. p. 205-219.

VIOLA, A. La crisis do desarrollismo y el surgimiento de la antropología del desarrollo. In: (Org.) Antropología del desarrollo. Barcelona: Paidós, 2000. p. 9-64.

ZHOURI, A.; OLIVEIRA, R. Desenvolvimento, conflitos sociais e violência no Brasil rural: O caso das usinas hidroelétricas. Ambiente \& Sociedade, São Paulo, v. 10, n. 02, p. 119-135, 2007.

MOÇAMBIQUE. Lei 19/97 de 01 de outubro: Lei de Terras. Boletim da República de Moçambique. I SERIE, n. 40, Maputo, 1997.

RODRIGUES, L. B.; ALVES, S.; NGUENHA, J. Constituição da República de Moçambique e Legislação Constitucional. Coimbra: Almedina, 2006. 